\section{GIn 63 of Rho is deamidated by Escherichia coli cytotoxic necrotizing factor-1}

\author{
Gudula Schmidt*, Peter Sehr ${ }^{\star}$, Matthias Wilm $\dagger$, \\ Jörg Selzer ${ }^{\star}$, Matthias Mann $\uparrow \&$ Klaus Aktories ${ }^{\star}$ \\ * Institut für Pharmakologie und Toxikologie der Albert-Ludwigs-Universität \\ Freiburg, Hermann-Herder-Strasse 5, 79104 Freiburg, Germany \\ $\dagger E M B L, 69012$ Heidelberg, Germany
}

The actin cytoskeleton is regulated by GTP-hydrolysing proteins, the Rho GTPases ${ }^{1,2}$, which act as molecular switches in diverse signal-transduction processes ${ }^{3}$. Various bacterial toxins can inactivate Rho GTPases by ADP-ribosylation ${ }^{1}$ or glucosylation ${ }^{4}$. Previous research has identified Rho proteins as putative targets for Escherichia coli cytotoxic necrotizing factors 1 and 2 (CNF1 and 2$)^{5,6}$. These toxins induce actin assembly and multinucleation in culture cells. Here we show that treatment of RhoA with CNF1 inhibits the intrinsic GTPase activity of RhoA and completely blocks GTPase activity stimulated by the Rho-GTPase-activating protein (rhoGAP). Analysis by mass spectrometry and amino-acid sequencing of proteolytic peptides derived from CNF1-treated RhoA indicate that CNF1 induces deamidation of a glutamine residue at position $63(\mathrm{G} \ln 63)$ to give constitutively active Rho protein.
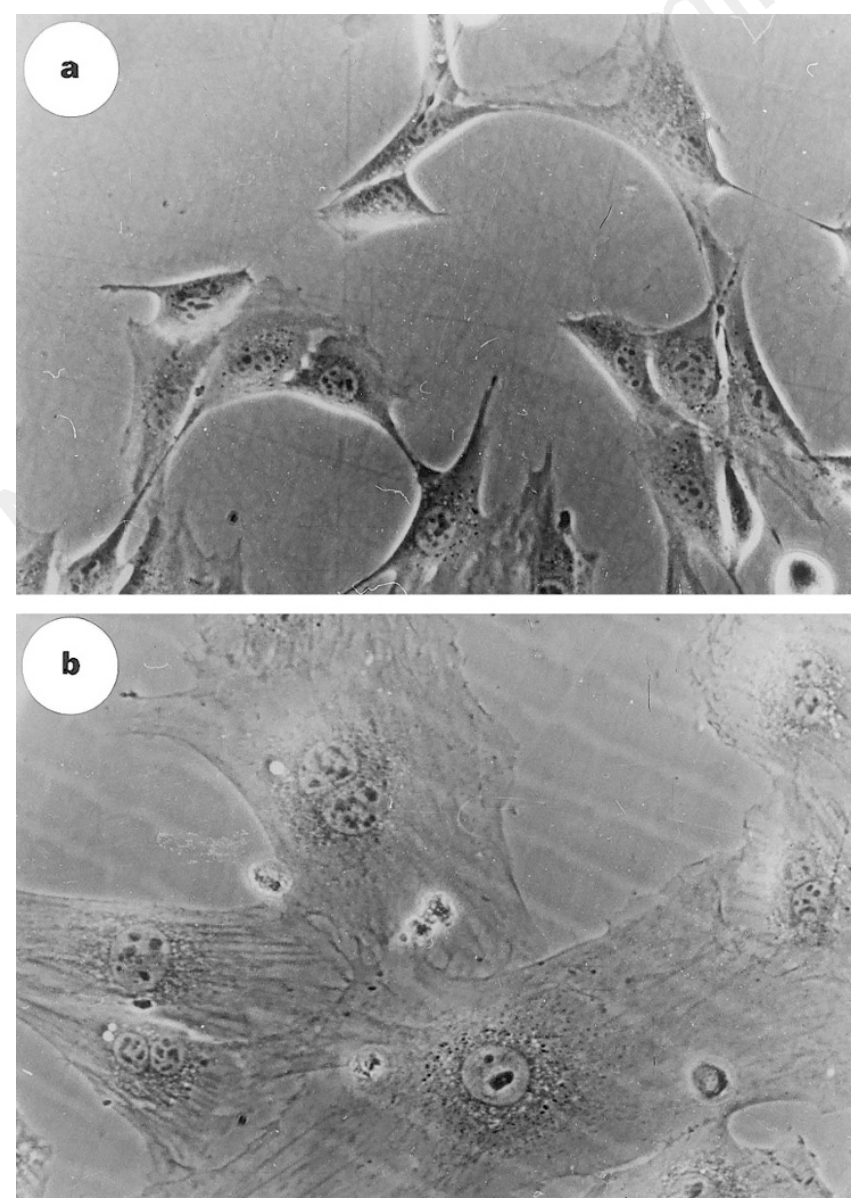

Figure 1 Induction of multinucleation and increase in F-actin by CNF1. NIH3T3 cells were treated without $(\mathbf{a}, \mathbf{c})$ and with CNF1 $\left(300 \mathrm{ng} \mathrm{ml}^{-1} ; \mathbf{b}, \mathbf{d}\right)$ for $16 \mathrm{~h}$. Cells were then analysed by phase-contrast microscopy $(\mathbf{a}, \mathbf{b})$ or the actin cytoskeleton
The cytotoxic necrotizing factors CNF1 and CNF2 (each of $M_{\mathrm{r}}$ $115 \mathrm{~K}$ ) are produced by up to half of the different $E$. coli strains isolated from extra-intestinal infections, and by up to a fifth of $E$. coli strains from diarrhoea ${ }^{7,8}$. These toxins cause tissue damage and death of the animal host ${ }^{8}$. CNFs induce actin polymerization and increase the F-actin content of cells ${ }^{6}$. They inhibit cytokinesis, cause formation of multinucleated cells, and induce membrane ruffling 9 . Because treatment of intact cells with CNFs changes the migration of Rho on SDS-PAGE, it has been suggested that CNFs act on Rho $^{5,6}$.

We expressed and purified CNF1 as a fusion protein with glutathione $S$-transferase (GST) and tested the activity of the recombinant toxin in NIH3T3 cells. GST-CNF1 (at $300 \mathrm{ng} \mathrm{ml}^{-1}$ ) induced multinucleation of $\sim 90 \%$ of cells after $24 \mathrm{~h}$ of treatment. Moreover, staining of the actin cytoskeleton with rhodaminephalloidin revealed a dense network of actin fibres resembling that induced by CNF1 (Fig. 1a-d).

Although major morphological changes in cells (multinucleation) were not observed earlier than $12-16 \mathrm{~h}$ after intoxication, treatment of cells with GST-CNF1 at $300 \mathrm{ng} \mathrm{ml}^{-1}$ for only $2-3 \mathrm{~h}$ altered the migration of Rho on SDS-PAGE. As shown in Fig. 2a, GST-CNF1 caused a shift in the apparent molecular mass of Rho protein labelled by $\mathrm{C} 3$-catalysed $\left[{ }^{32} \mathrm{P}\right] \mathrm{ADP}$-ribosylation, indicating that the GTPase has been covalently modified. This change in migration induced by GST-CNF1 was also observed after ${ }^{14} \mathrm{C}$ glucosylation of Rho by Clostridium difficile toxin B (not shown).

Treatment of recombinant RhoA with GST-CNF1 (molar ratio $16: 1)$ for $3 \mathrm{~h}$ at $37^{\circ} \mathrm{C}$ caused a similar shift in the apparent molecular mass of $\left[{ }^{32} \mathrm{P}\right]$ ADP-ribosylated RhoA on SDS-PAGE, as
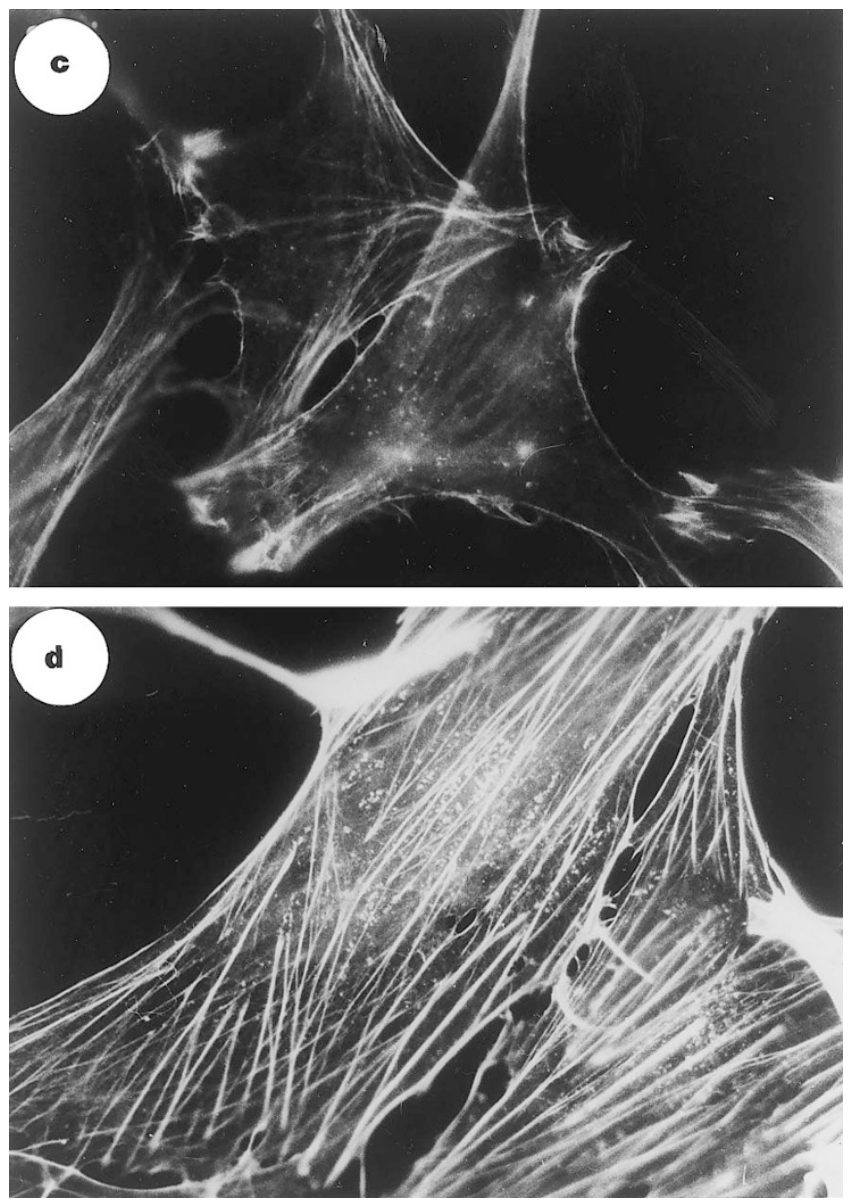

was stained with rhodamine-labelled phalloidin for fluorescence microscopy (c, d). 
a

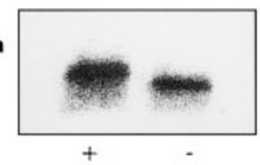

b
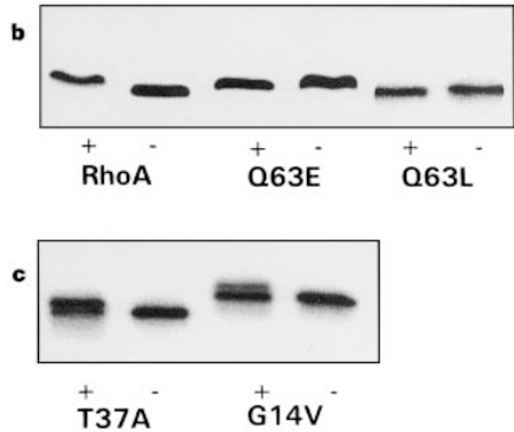

c
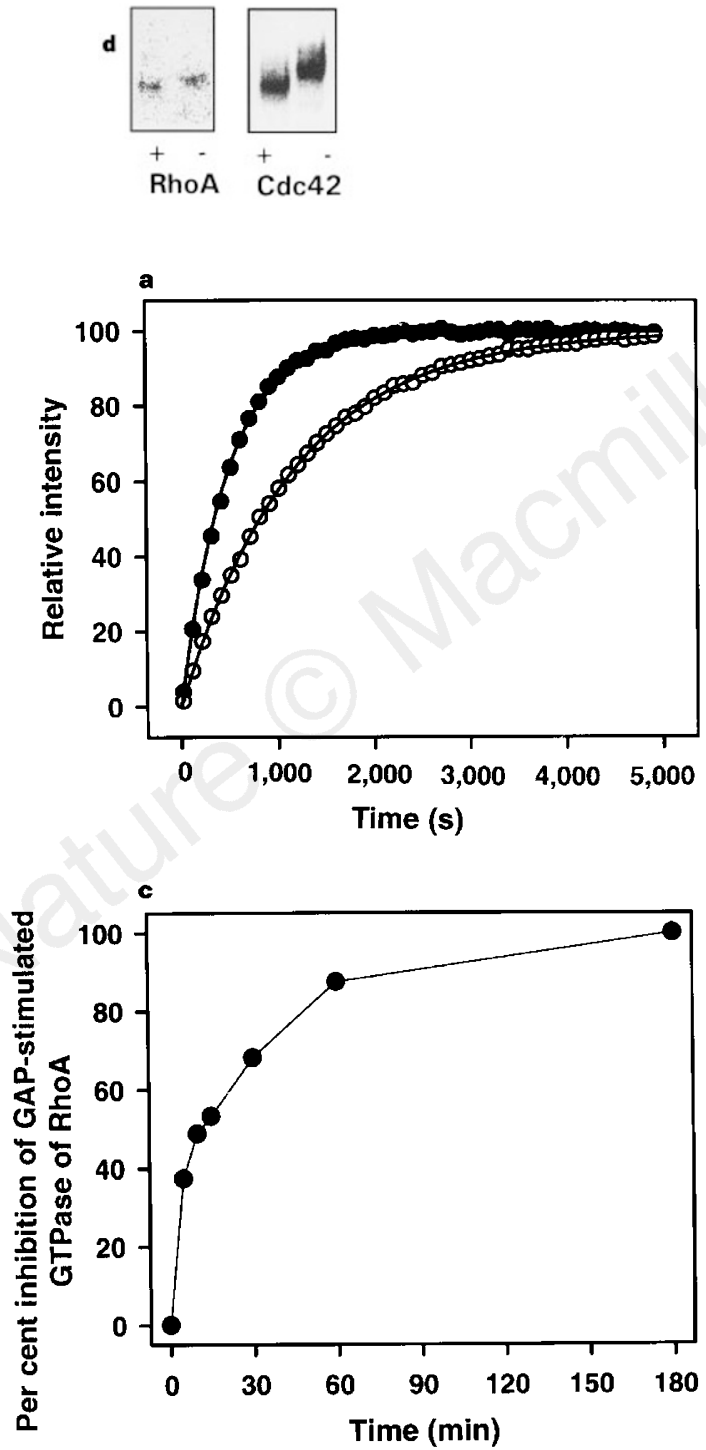

Figure $3 \mathbf{a}$, Nucleotide-binding of CNF1-treated RhoA. Binding of mantGDP to RhoA previously treated without $(\bullet)$ and with $(O)$ GST-CNF1 (ratio of RhoA : CNF1 was 16:1) was followed as the increase in fluorescence intensity. b, GTPase activity of CNF1-treated RhoA. RhoA was treated without $(\bullet, \mathbf{\square})$ and with GST$\operatorname{CNF} 1(\square, 0)$ at a ratio of $16: 1$. Thereafter, $\left[\gamma^{-}{ }^{32} P\right]$ GTP was bound and the GTPase incubated in the absence $(\boldsymbol{\bullet}, 0)$ and presence of rhoGAP $(40 \mathrm{nM} ; \boldsymbol{\square}, \square)$ for the times given (final concentrations of Rho proteins, $0.8 \mu \mathrm{M}$ ). Radioactivity remaining on the GTPase was determined in a filter-binding assay as described in Methods.
Figure 2 Effects of CNF1 on the migration behaviour of Rho. a, Cells were treated without ( - ) and with (+) GST-CNF1 (300 ng ml ${ }^{-1}$ ) for 16 h. b, c, WT-RhoA (RhoA), mutant Gln63Glu-RhoA (Q63E), Gln63Leu-RhoA (Q63L), Thr37Ala-RhoA (T37A) and Gly14Val-RhoA (G14V) were treated without ( - ) and with GST-CNF1 (+) at a ratio of $10: 1$ for $3 \mathrm{~h}$. Cell lysates and recombinant Rho proteins were [ ${ }^{32} \mathrm{P}$ ]ADPribosylated by transferase $\mathrm{C} 3$. Labelled proteins were analysed by SDS-PAGE and phosphorimaging. d, RhoA and Cdc42 were treated without ( - ) and with GST-CNF1 (+) at a ratio of $16: 1$ and $2: 1$, respectively, for $3 \mathrm{~h}$. Thereafter, GTPases were ${ }^{14} \mathrm{C}$-glucosylated by $\mathrm{C}$. difficile toxin $\mathrm{B}$ and analysed by non-denaturing gel electrophoresis and phosphorimaging.
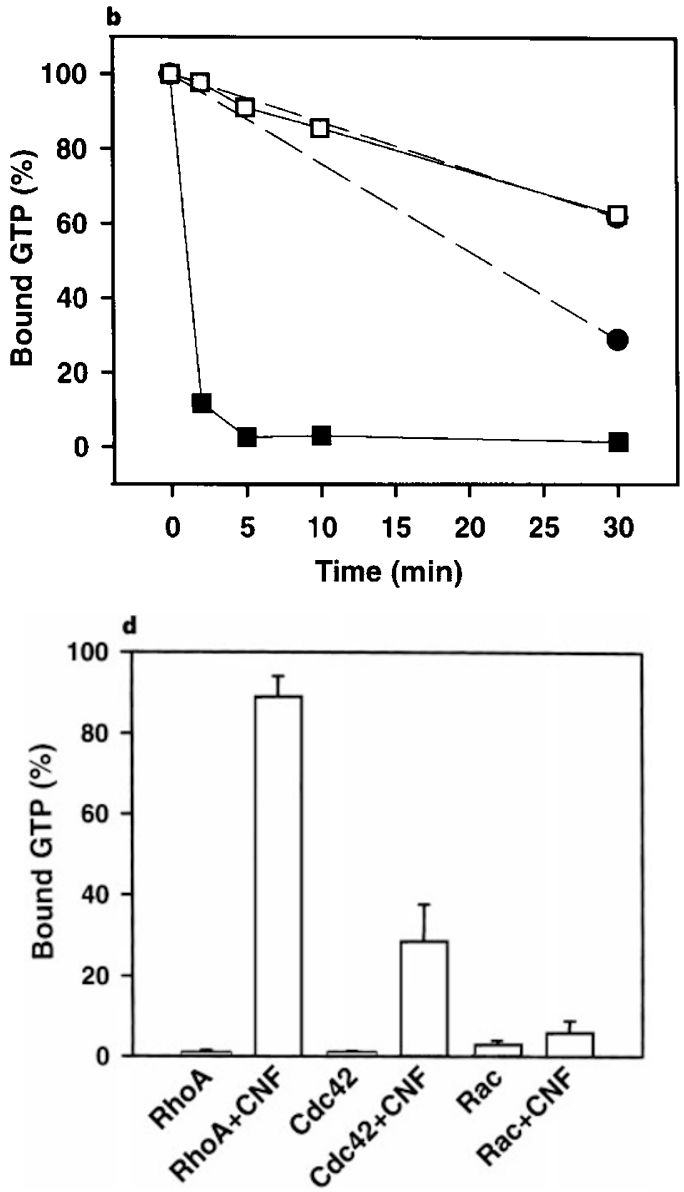

c, Time-dependent inhibition of GAP-stimulated GTP hydrolysis by CNF1. RhoA was treated with GST-CNF1 (ratio 16:1) for the indicated times. The inhibition of GAP-stimulated GTPase activity of RhoA is shown as per cent of maximum. Without CNF treatment, the remaining radioactivity was $97 \%$ and $16 \%$ in the absence and presence of GAP, respectively. $\mathbf{d}$, Influence of CNF1 on stimulation of GTPase activity of RhoA, Rac1 and Cdc42 by rhoGAP. RhoA, Rac1 and Cdc42 were treated with GST-CNF1 at a ratio of $16: 1$. 
after treatment of intact cells with the toxin (Fig. 2b). In contrast, when RhoA was incubated with heat-inactivated GST-CNF1 $\left(15 \mathrm{~min}\right.$ at $\left.95^{\circ} \mathrm{C}\right)$ or without toxin, the migration of the GTPase was unaffected (results not shown).

Next we studied the effects of GST-CNF1 on nucleotide-binding of RhoA by monitoring the increase in fluorescence intensity of mantGDP (see Methods) ${ }^{10}$. As shown in Fig. 3a, total mantGDP binding was the same as for the control and CNF-treated RhoA, indicating that the GTPase structure was native. MantGDP binding (indicative of the release of previously bound nucleotide) was about twofold slower after toxin treatment. Figure $3 \mathrm{~b}$ shows the influence of CNF1 on rhoGTPase activity. Basal GTPase activity of control RhoA was stimulated $\sim 20$-fold by p50 rhoGAP protein $\left(M_{\mathrm{r}} 50 \mathrm{~K}\right)$ at $40 \mathrm{nM}$. Treatment of RhoA with GST-CNF1 decreased the basal GTPase activity and completely blocked GAP-stimulated GTP hydrolysis. We checked that this effect was not due to changes in buffer or cation concentrations. Heat inactivation completely blocked CNF1 effects on Rho GTPase activity (not shown). The time course (Fig. 3c) shows that inhibition of GAP-stimulated GTPase activity was half-maximal after GST-CNF1 treatment of RhoA for $10 \mathrm{~min}$; inhibition was complete after $2-3 \mathrm{~h}$.

Next we studied the effects of CNF1 on GAP-stimulated GTP hydrolysis by the Rho GTPases Cdc42 and Rac1. Whereas CNF1 (at a molar ratio of GTPase to CNF1 of $16: 1$ ) part inhibited GAP stimulation of Cdc42 ( $\sim 30 \%)$, Rac1 GTPase activity was hardly affected by CNF1 treatment at this toxin concentration, suggesting that CNF1 acts preferentially with Rho (Fig. 3d). At higher concentrations of CNF1 (molar ratio of GTPase to CNF1 of $2: 1$ ), the GAP-stimulated GTPase activity of Rho, Cdc42 and Rac was inhibited by $>90,60$ and $38 \%$, respectively. We checked a possible covalent modification of the GTPase on SDS-PAGE. No change in the migration of CNF1-treated Cdc42 was detected on SDS-PAGE, but treated $\mathrm{Cdc} 42$ migrated faster than controls on non-denaturing gels (Fig. 2d). CNF-modified RhoA behaved like Cdc42 (Fig. 2d) (Rac gave no clear band in non-denaturing gels).

To identify the structural changes induced by CNF1 that were responsible for inhibiting GTPase activity and activating Rho, we used mass spectrometric (MS) analysis. Measurements of control and CNF1-treated RhoA showed an upward shift in mass for the toxin-treated GTPase of 1 to 3 daltons. Comparison of the tryptic peptide maps of the two proteins revealed a $2 \mathrm{~K}$ peptide whose mass was shifted by 1 dalton between the two proteins (from $2.008 \mathrm{~K}$ to $2.009 \mathrm{~K}$ for CNF1-treated RhoA). The doubly charged ion was sequenced by tandem mass spectrometry. The fragment spectrum of the peptide from the untreated RhoA corresponded to the sequence from Gln 52 through to Arg 68 (QVELALWDTAGQEDYDR). The tandem MS spectrum of CNF1-treated RhoA showed that the Gln 63 residue was deamidated to glutamic acid (Fig. 4), thereby explaining the observed mass difference between the two peptides. Moreover, a toxin-induced deamidation is consistent with the finding that in vitro modification of Rho by CNF did not depend on any added cofactor such as NAD ${ }^{+}$

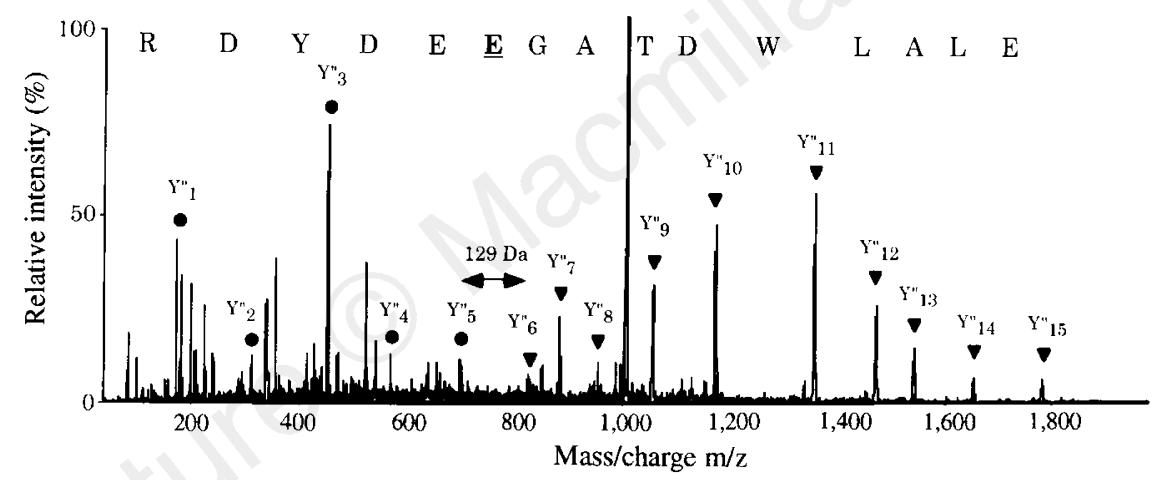

Figure 4 Tandem MS spectrum of the doubly charged tryptic peptide Gln 52-Arg 68 of the CNF Iexposed RhoA. The sequence of the peptide is reflected by the continuous $\mathrm{Y}^{\prime \prime}$ ion series, the Cterminal sequence ions of the peptide. The mass difference between the $Y_{5}^{\prime \prime}$ and $Y_{6}^{\prime \prime}$ ion is 129 daltons, corresponding to a glutamic acid. When comparing the tandem MS spectra of the peptides from untreated and CNF I-treated RhoA the $Y_{1}^{\prime \prime}-Y_{5}^{\prime \prime}$ ions are at the same position (marked by $\bullet$ in the spectrum), whereas the $Y_{6}^{\prime \prime}-Y_{15}^{\prime \prime}$ ions are shifted upwards by 1 dalton $(\mathbf{v})$, indicative of the deamidation of Gln 63.

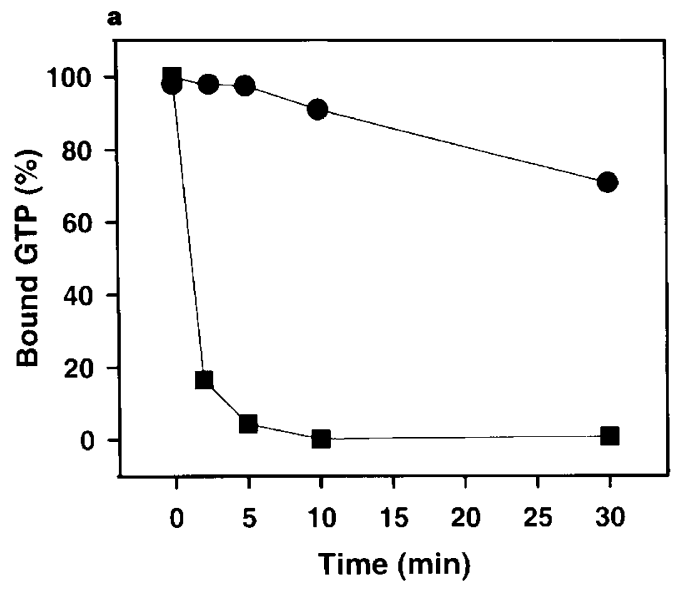

Figure 5 GTPase activity and nucleotide-binding of Gln63Glu-RhoA. a, $\left[\gamma^{-32} P\right] G T P$ was bound to Gln63Glu-RhoA ( $\bullet$ ) or wild-type RhoA ( $\mathbf{\square}$; each at a final concentration of $0.8 \mu \mathrm{M})$ and the GTPases were incubated with p50 rhoGAP ( $40 \mathrm{nM})$ for the times indicated. Radioactivity remaining on the GTPase was determined in a

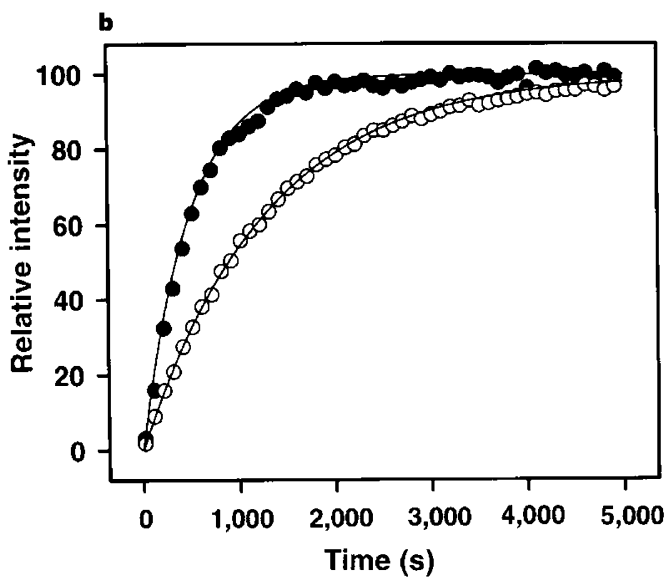

filter-binding assay as described in Methods. b. Time course of binding of mantGDP (showing the release of prebound nucleotide) to wild-type RhoA (or GIn63Glu-RhoA (O) was followed by the increase in mant-fluorescence intensity. 


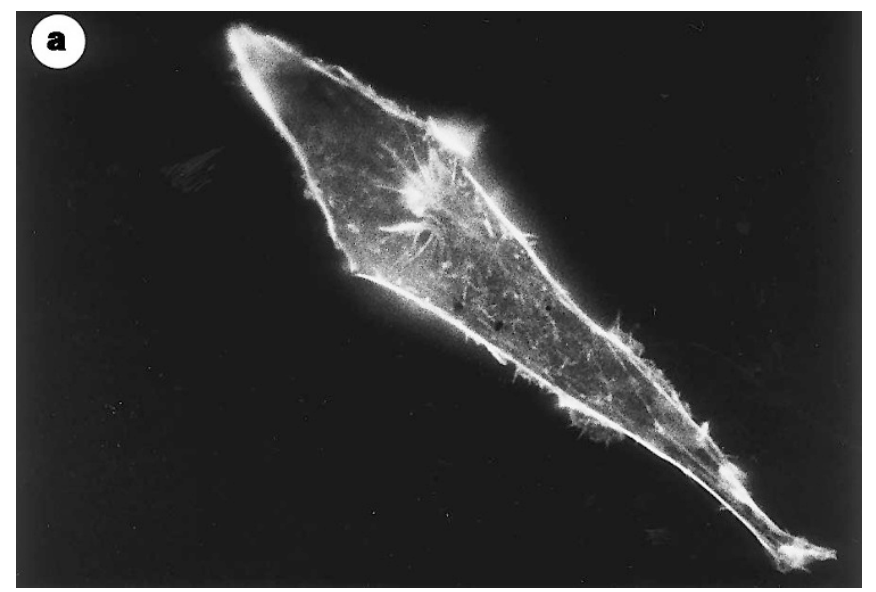

Figure 6 Induction of stress fibres by microinjection of GIn63Glu-RhoA. To avoid wild-type RhoA-induced effects on the actin cytoskeleton, CAAX-box-deleted $(\Delta \mathrm{CLVL})$ proteins were used for microinjection. Recombinant Gln63Glu-RhoA protein $\left(2 \mathrm{mg} \mathrm{ml}^{-1} ; \mathbf{b}\right)$ but not the control RhoA $\left(2 \mathrm{mg} \mathrm{ml}^{-1} ; \mathbf{a}\right)$ induced formation of

or UDP-glucose, which are essential for modification of the GTPase by C3-like ADP-ribosyltransferases and clostridial glucosyltransferases, respectively.

To corroborate a role of Gln 63 in CNF1-induced covalent modification of RhoA, we constructed a Gln63Glu mutant of RhoA, in which a glutamate residue is substituted for glutamine at position 63, expressed it in E. coli, then purified and tested it as a substrate for CNF1. As shown in Fig. 2b, treatment of Gln63GluRhoA with GST-CNF1 did not cause a shift in the SDS-PAGE pattern. Even without toxin treatment, this protein migrated slightly more slowly than wild-type RhoA. Similarly, there was no change in migration after treatment of Gln63Leu-RhoA with CNF1. In contrast, a shift was induced by CNF1 in the control mutant proteins Thr37Ala- and Gly14Val-RhoA (Fig. 2c). As for CNF1treated RhoA, GAP stimulation of GTP hydrolysis was blocked in the mutant Gln63Glu-RhoA (Fig. 5a) and mantGDP binding of this mutant was slowed by a factor of two (preloading of the GTPase with GDP did not change this effect) (Fig. 5b). Moreover, microinjection of Gln63Glu-RhoA into NIH3T3 cells induced the formation of stress fibres (Fig. 6), as reported for the Gln63Leu-RhoA mutation $^{11}$. We did not observe multinucleation after microinjection of Gln63Glu-RhoA even after prolonged incubation $(24 \mathrm{~h})$. This discrepancy in the effect of CNF in intact cells could be explained by modification of other Rho subfamily proteins (for example, Cdc42).

Gln 63 of Rho is essential for GTPase activity. For example, mutation of this residue to leucine inhibits GTPase, blocks GAP stimulation and induces dominant positive activity of the GTPase $^{12,13}$. In Ras, the function of the equivalent residue (Gln 61) has been studied in more detail. Mutation of Gln 61 to almost any other amino acid blocks both intrinsic and GAP-stimulated GTPase activity $^{14,15}$. This glutamine residue in Ras may act either as a general base to activate water for nucleophilic attack or it could be involved in stabilizing the transition state of the GTPase reaction ${ }^{15}$; Gln 63 in Rho may have a similar role. Thus deamidation of this pivotal glutamine residue, resulting in the formation of constitutively active Rho proteins, is a new mode of action for intracellularly acting toxins.

\section{Methods}

Materials. $\left[{ }^{32} \mathrm{P}\right] \mathrm{NAD}^{+}$and $\mathrm{UDP}-\left[{ }^{14} \mathrm{C}\right]$ glucose were obtained from DuPont NEN. Wild-type RhoA, Rac1, Cdc42, Gly14Val-RhoA, Thr37Ala-RhoA, Gln63Leu-RhoA and p50 rhoGAP (the latter two expression constructs were from A. Hall) were prepared from their fusion proteins (for example, RhoA-

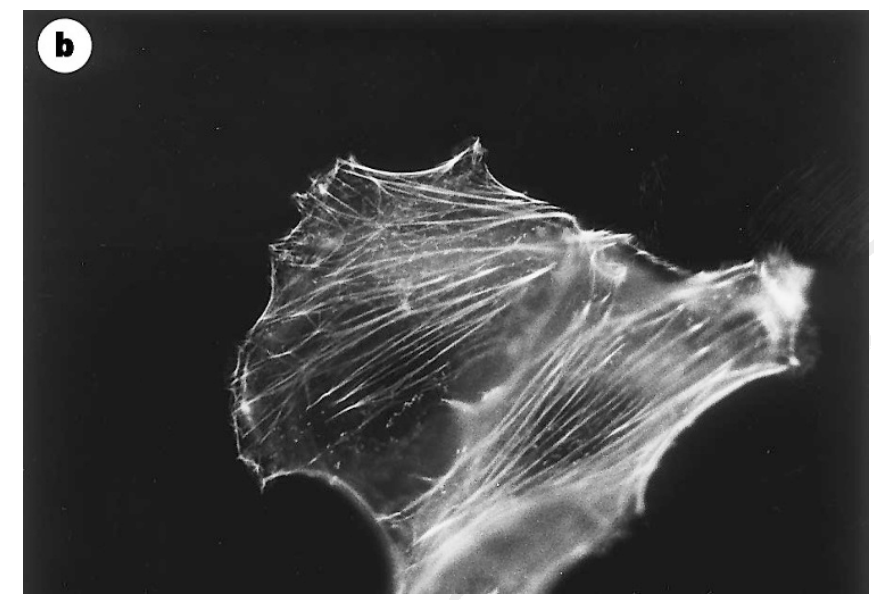

actin stress fibres after microinjection into NIH3T3 cells. One hour after microinjection, cells were fixed and stained for F-actin by rhodamine-conjugated phalloidin. The fluorescence micrograph is shown.

GST) as described ${ }^{16}$. Gln63Glu-RhoA and truncated $\Delta$ CLVL Rho proteins were generated using a polymerase chain reaction (PCR)-based mutagenesis system and the proper DNA sequence was checked. $N$-methylanthraniloyl GDP (mantGDP) was prepared as described ${ }^{17}$.

Cloning and purification of GST-CNF1. The CNF1 gene with flanking $B a m \mathrm{HI}$ and EcoR1 sites was generated by PCR from the vector PISS 391 (ref. 18; a gift from J. Hacker) and cloned in-frame into the expression vector pGEX2TGL +2 . The proper construct was checked by DNA sequencing. The GST fusion protein was isolated by affinity chromatography with glutathioneSepharose (Pharmacia).

Cell culture. NIH3T3 cells were grown in Dulbecco's modified Eagles medium supplemented with $10 \%$ fetal calf serum in humidified $\mathrm{CO}_{2}(5 \%)$ at $37^{\circ} \mathrm{C}$. After washing with PBS, cells were scraped off and lysed by sonication in lysis buffer (20 mM TEA, pH 7.4, 2 mM $\mathrm{MgCl}_{2}, 2 \mathrm{mM}$ EDTA, $1 \mathrm{mM}$ PMSF, $0.4 \mathrm{mg} \mathrm{ml}^{-1}$ aprotinin and $0.4 \mathrm{mg} \mathrm{ml}^{-1}$ benzamidine). Cell debris and whole cells were eliminated by centrifugation ( $30 \mathrm{~min}, 14,000$ r.p.m.) and the protein concentration of the cell lysate was determined. For actin staining, cells were treated for $16-24 \mathrm{~h}$ with GST-CNF1 (300 $\left.\mathrm{ng} \mathrm{ml}^{-1}\right)$.

Actin staining. CNF1-treated and control cells were washed 3 times with icecold PBS, pH 7.4, and fixed with 4\% formaldehyde, $0.1 \%$ Tween 20 in PBS at room temperature for $10 \mathrm{~min}$. After intensive washing with PBS, cells were incubated with rhodamine-conjugated phalloidin (1 unit per coverslip) at room temperature in a humidified atmosphere for $60 \mathrm{~min}$, washed again, and applied for fluorescence microscopy.

Microinjection. For microinjection, CAAX-box-deleted recombinant wildtype RhoA and Gln63Glu-RhoA $\left(2 \mathrm{mg} \mathrm{ml}^{-1}\right.$ each) were microinjected into NIH3T3 cells with a Microinjector 5242 (Eppendorf). After $1 \mathrm{~h}$, cells were fixed and stained for F-actin by rhodamine-phalloidin as described.

ADP-ribosylation and glucosylation assays. For ADP-ribosylation ${ }^{19}$, cell lysates were adjusted to the same protein concentration $\left(1.5 \mathrm{mg} \mathrm{ml}^{-1}\right)$. Lysates or purified proteins $\left(30 \mu \mathrm{g} \mathrm{ml}^{-1}\right)$ were incubated with $C$. botulinum exoenzyme C3 $\left(0.5 \mu \mathrm{g} \mathrm{ml}^{-1}\right)$ and $1 \mu \mathrm{M}\left[{ }^{32} \mathrm{P}\right] \mathrm{NAD}^{+}(\sim 0.1 \mu \mathrm{Ci}$ per tube $)$ in $50 \mu \mathrm{l}$ ADP-ribosylation buffer ( $25 \mathrm{mM}$ triethanolamine- $\mathrm{HCl}, \mathrm{pH} 7.5,2 \mathrm{mM} \mathrm{MgCl}_{2}$, $1 \mathrm{mM} \mathrm{DTT}$ ) at $37^{\circ} \mathrm{C}$ for $15 \mathrm{~min}$. The reaction was terminated by addition of $10 \mu \mathrm{l}$ stop reagent $(10 \% \mathrm{SDS}, 10 \mathrm{mM} \mathrm{DTT})$ and heated for $5 \mathrm{~min}$ at $95^{\circ} \mathrm{C}$. Thereafter, $20 \mu \mathrm{l} 15 \mathrm{mM} N$-ethylmaleimide was added and the samples incubated at room temperature for $15 \mathrm{~min}$. Proteins were analysed by SDS-PAGE and phosphorimaging (Molecular Dynamics). For glucosylation recombinant proteins $\left(50 \mu \mathrm{g} \mathrm{ml}^{-1}\right)$ or cell lysates $\left(1.5 \mathrm{mg} \mathrm{ml}^{-1}\right.$ protein) were incubated with toxin $\mathrm{B}\left(1 \mu \mathrm{g} \mathrm{ml}^{-1}\right)$ in a buffer containing $10 \mu \mathrm{M}$ UDP- $\left[{ }^{14} \mathrm{C}\right]$ glucose, $10 \mathrm{mM}$ HEPES (pH 7.4) and $150 \mathrm{mM} \mathrm{KCl}$ for $30 \mathrm{~min}$ at $37^{\circ} \mathrm{C}$. Glucosylated proteins were analysed by SDS-PAGE or by non-denaturing gel electrophoresis and phosphorimaging as described. ${ }^{20}$

In vitro modification of GTPases by CNF1. Small GTPases were treated 
essentially as described for modification of Rho with dermonecrotic toxin $(\mathrm{DNT})^{21}$. In general, recombinant proteins were incubated with GST-CNF1 in a molar ratio of $10: 1$ or 16:1 (GTPase:GST-CNF1) (or as indicated) in a reaction buffer containing $20 \mathrm{mM}$ Tris- $\mathrm{HCl}, \mathrm{pH} 7.5,10 \mathrm{mM} \mathrm{MgCl}_{2}, 1 \mathrm{mM}$ DTT, $1 \mathrm{mM}$ EDTA for $3 \mathrm{~h}$ at $37^{\circ} \mathrm{C}$.

Nucleotide-binding assay. RhoA was modified as described above but with GST-CNF1 immobilized to glutathione-Sepharose beads to remove the toxin after the reaction. $0.5 \mu \mathrm{M}$ RhoA, CNF1-modified RhoA or Gln63Glu-RhoA were incubated in buffer $\mathrm{C}(150 \mathrm{mM} \mathrm{NaCl}, 2.5 \mathrm{mM} \mathrm{MgCl}, 10 \mathrm{mM}$ triethanolamine- $\mathrm{HCl}, \mathrm{pH} 7.5$ ) at $37^{\circ} \mathrm{C}$. After addition of $2 \mu \mathrm{M}$ mantGDP, the increase in mant-fluorescence upon binding to RhoA was monitored in a Perkin Elmer LS50B luminescence spectrometer. The emission was measured at $444 \mathrm{~nm}$ with excitation at $357 \mathrm{~nm}$.

GTPase assay. Recombinant Rho proteins modified by CNF1 were loaded with $\left[\gamma^{-}{ }^{32} \mathrm{P}\right] \mathrm{GTP}$ for $5 \mathrm{~min}$ at $37^{\circ} \mathrm{C}$ in loading buffer $(10 \mathrm{mM}$ EDTA, $2 \mathrm{mM}$ DTT, $50 \mathrm{mM}$ Tris- $\mathrm{HCl}, \mathrm{pH}$ 7.5). $\mathrm{MgCl}_{2}$ was then added to $12 \mathrm{mM}$. Unbound nucleotide was removed by gel filtration or unlabelled GTP $(5 \mathrm{mM})$ was added. For GAP stimulation, $40 \mathrm{nM}$ of p50 rhoGAP was added (Rho at $0.8 \mu \mathrm{M}$ ). GTPase activities were determined by measuring the loss of protein-bound radioactivity in a filter-binding assay ${ }^{1}$.

Mass spectrometric analysis. All electrospray experiments were done on a triple quadrupole instrument (API III, Perkin-Elmer). CNFI-exposed and untreated RhoA were desalted on a $100 \mathrm{nl}$ RI Poros microcolumn as described ${ }^{22}$. They were eluted in $2 \times 0.5 \mu \mathrm{l} 50 \%$ acetonitrile, $5 \%$ formic acid into a nano electrospray spraying needle for mass spectrometry.

The proteins were digested with trypsin (Boehringer Mannheim, sequencing grade) for $5 \mathrm{~h}$. The peptide mixture was step-eluted with $2 \times 0.4 \mu \mathrm{l} 50 \%$ methanol, $5 \%$ formic acid into the emitter of the nano electrospray ion source.

Received 14 March; accepted 17 April 1997.

1. Paterson, H. F. Microinjection of recombinant $\mathrm{p} 21^{\text {rho }}$ induces rapid changes in cell morphology. J. Cell Biol. 111, 1001-1007 (1990).

2. Machesky, L. M. \& Hall, A. Rho: A connection between membrane receptor signalling and the cytoskeleton. Trends Cell Biol. 6, 304-310 (1996).

3. Lim, L., Manser, E., Leung, T. \& Hall, C. Regulation of phosphorylation pathways by p21 GTPasesthe p21 Ras-related Rho subfamily and its role in phosphorylation signalling pathways. Eur. J. Biochem. 242, 171-185 (1996).

4. Just, I. et al. Glucosylation of Rho proteins by Clostridium difficile toxin B. Nature 375, 500-503 (1995).

Oswald, E. et al. Cytotoxic necrotizing factor type 2 produced by virulent Escherichia coli modifies the small GTP-binding proteins Rho involved in assembly of actin stress fibers. Proc. Natl Acad. Sci. USA 91, 3814-3818 (1994)

6. Fiorentini, C. et al. Escherichia coli cytotoxic necrotizing factor 1: Evidence for induction of actin assembly by constitutive activation of the p21 Rho GTPase. Infect. Immun. 63, 3936-3944 (1995). Caprioli, A., Falbo, V., Roda, L. G., Ruggeri, F. M. \& Zona, C. Partial purification and characterization of an Escherichia coli toxic factor that induces morphological cell alterations. Infect. Immun. 39, 13001306 (1983).

8. de Rycke, J. et al. Evidence for two types of cytotoxic necrotizing factor in human and animal clinical isolates of Escherichia coli. J. Clin. Microbiol. 28, 694-699 (1990).

9. Falzano, L. et al. Induction of phagocytic behaviour in human epithelial cells by Escherichia coli cytotoxic necrotizing factor type 1. Mol. Microbiol. 9, 1247-1254 (1993).

10. Leonard, D. A., Evans, T., Hart, M., Cerione, R. A. \& Manor, D. Investigation of the GTP-binding/ GTPase cycle of Cdc42Hs using fluorescence spectroscopy. Biochemistry 33, 12323-12328 (1994).

11. Ridley, A. J. Microinjection of Rho and Rac into quiescent Swiss 3T3 cells. Methods Enzymol. 256, 313-320 (1995)

12. Diekmann, D. \& Hall, A. In vitro binding assay for interactions of Rho and Rac with GTPase-activating proteins and effectors. Methods Enzymol. 256, 207-215 (1995).

13. Renshaw, M. W., Toksoz, D. \& Schwartz, M. A. Involvement of the small GTPase Rho in integrinmediated activation of mitogen-activated protein kinase. J. Biol. Chem. 271, 21691-21694 (1996).

14. Der, C. J., Finkel, T. \& Cooper, G. M. Biological and biochemical properties of human $\operatorname{ras}^{\mathrm{H}}$ genes mutated at codon 61. Cell 44, 167-176 (1986)

15. Schweins, T. et al. Substrate-assisted catalysis as a mechanism for GTP hydrolysis of $\mathrm{p} 21^{\text {ras }}$ and other GTP-binding proteins. Nature Struct. Biol. 2, 36-44 (1995).

16. Just, I. et al. Clostridium difficile toxin B acts on the GTP-binding protein Rho. J. Biol. Chem. 269, 10706-10712 (1994)

17. Hiratsuka, T. New ribose-modified fluorescent analogs of adenine and guanine nucleotides available as substrates for various enzymes. Biochim. Biophys. Acta 742, 496-508 (1983).

18. Falbo, V., Pace, T., Picci, L., Pizzi, E. \& Caprioli, A. Isolation and nucleotide sequence of the gene encoding cytotoxic necrotizing factor 1 of Escherichia coli. Infect. Immun. 61, 4909-4914 (1993).

19. Aktories, K. \& Just, I. In vitro ADP-ribosylation of Rho by bacterial ADP-ribosyltransferases. Methods Enzymol. 256, 184-195 (1995).

20. Just, I., Selzer, J., Von Eichel-Streiber, C. \& Aktories, K. The low molecular mass GTP-binding protein Rho is affected by toxin A from Clostridium difficile. J. Clin. Invest. 95, 1026-1031 (1995).

21. Horiguchi, Y., Senda, T., Sugimoto, N., Katahira, J. \& Matsuda, M. Bordetella bronchiseptica dermonecrotizing toxin stimulates assembly of actin stress fibers and focal adhesions by modifying the small GTP-binding protein rho. J. Cell Sci. 108, 3243-3251 (1995).

22. Wilm, M. \& Mann, M. Analytical properties of the nanoelectrospray ion source. Anal. Chem. 68, 1-8 (1996).

Acknowledgements. We thank I. Just for critical reading of the manuscript.

Correspondence and requests for materials should be addressed to K.A. (e-mail: aktories@ruf.unifreiburg.de)

\section{Toxin-induced activation of the G protein p21 Rho by deamidation of glutamine}

\section{Gilles Flatau ${ }^{\star}$ Emmanuel Lemichez ${ }^{\star}$, Michel Gauthier*, Pierre Chardin $\dagger$, Sonia Paris $\dagger$, Carla Fiorentini $\ddagger$ \& Patrice Boquet*}

* INSERM U452, Faculté de Médecine, avenue de Valombrose, Nice 06107,

Cedex 2, France

$\dagger$ Institut de Pharmacologie Moléculaire et Cellulaire du CNRS, route des Lucioles, Sophia Antipolis, Valbonne 06560, France

$\ddagger$ Department of Ultrastructures, Istituto Superiore di Sanità, viale Regina Elena, 00161, Roma, Italy

Pathogenic Escherichia coli are responsible for a variety of diseases, including diarrhoea, haemolytic uraemic syndrome, kidney infection, septicaemia, pneumonia and meningitis. Toxins called cytotoxic necrotizing factors (CNFs) are among the virulence factors produced by uropathogenic $(\mathrm{CNF} 1)^{1}$ or enteropathogenic $(\mathrm{CNF} 2)^{2}$ E. coli strains that cause diseases in humans and animals, respectively. CNFs induce an increase in the content of actin stress fibres and focal contacts in cultured cells ${ }^{3,4}$. Effects of CNFs on the actin cytoskeleton correlated with a decrease in the electrophoretic mobility of the GTP-binding protein $\mathrm{Rho}^{4,5}$ and indirect evidence indicates that CNF1 might constitutively activate Rho $^{6}$. Here we show that CNF1 catalyses the deamidation of a glutamine residue at position 63 of Rho, turning it into glutamic acid, which inhibits both intrinsic GTP hydrolysis and that stimulated by its GTPaseactivating protein (GAP). Thus, this deamidation of glutamine 63 by CNF1 leads to the constitutive activation of Rho, and induces the reorganization of actin stress fibres. To our knowledge, CNF1 is the first example of a bacterial toxin acting by deamidation of a specific target protein.

Incubation of Vero cells with CNF1 induces actin stress fibre accumulation and cell spreading (Fig. 1a, b), with a concomitant decrease in the electrophoretic mobility of the Rho protein on SDSPAGE (Fig. 1c). Incubation of recombinant RhoA with purified CNF1 in vitro gives the same mobility shift as that observed after in vivo treatment (Fig. 2). This result indicates that CNF1 directly modifies Rho without the need for cellular cofactors. Incubation with CNF1 did not modify the electrophoretic mobilities of Rac, Cdc42, Rab6 or Ras either in vivo or in vitro (data not shown). In vitro induction of the mobility shift by CNF1 was blocked by heat denaturation of either RhoA or CNF1 (Fig. 2). To analyse the modification induced by CNF1, we eluted RhoA treated with CNF1 in vitro, untreated RhoA, or a mixture of both from gels and digested the eluate with trypsin. Separation of the tryptic peptides on a DEAE C-18 HPLC column yielded three major peptides $(A, B, C)$; peptide B in CNF1-treated RhoA eluted slightly later than peptide $B$ from untreated RhoA (Fig. 3a, top and middle panels). In the sample containing both CNF1-treated and untreated RhoA, peptide B is duplicated (Fig. 3a, lower panel). Peptide B1 elutes as peptide $B$ from the untreated RhoA sample, whereas peptide B2 elutes as peptide B from CNF1-treated RhoA (Fig. 3a). Amino-acid sequencing of peptide B from untreated RhoA yielded the sequence QVELALWDTAGQEDYDR, corresponding to amino acids 52-68 of RhoA ${ }^{7}$, whereas in CNF1-treated RhoA the sequence was QVELALWDTAGEEDYDR, which differs only by having a glutamic acid residue at position 63 instead of glutamine. Accordingly, in the CNF1-treated and untreated RhoA mixture, the aminoacid sequence of the B1 peptide corresponded exactly to RhoA 5268 , whereas the B2 peptide had the single Q63E modification of CNF1-treated RhoA. Apart from Gln 63, RhoA contains two additional glutamine residues in positions 29 and 52 (ref. 7) which were 